\title{
O DIREITO PENAL E A REVOLUÇÃO: ANÁLISE DA CRIMINALIZAÇÃ̃O DOS MOVIMENTOS SOCIAIS SOB A PERSPECTIVA DA REVOLUÇÃO EM HANNAH ARENDT
}

Daniela Ferreira dos Reis João Carlos Cunha Moura

ISSUE DOI: $10.21207 / 1983.4225 .308$

\section{RESUMO}

O presente artigo tem por objetivo analisar os estudos de Hannah Arendt sobre o exercício da cidadania e da política, nos quais aborda a Revolução como parte da luta pela liberdade política dos Movimentos Sociais e apresenta a noção da criminalização como ferramenta de controle social. A partir da exposição a respeito do Direito e da estrutura de controle dos grupos marginalizados por meio do Direito Penal e dos meios de comunicação de massa, pretende-se analisar a Criminalização no contexto jurídico e social, bem como defender a luta dos Movimentos Sociais, sob a perspectiva da necessidade de mudança completa da estrutura jurídica, por meio da revolução social. Neste trabalho, será utilizado o método exploratório, haja vista que visa à explanação sobre o tema delimitado e à ampliação do conhecimento. 
Palavras-Chave: Direito Penal. Movimentos Sociais. Revolução. Criminalização.

\section{INTRODUÇÃO}

A sociedade se constitui hoje na prática de direito democrático que se caracteriza por limitar o conceito de cidadania atrelando-o ao agir conforme os deveres e direitos positivados. Como uma espécie de braço do sistema jurídico, o Direito Penal emana com a pretensão de assegurar esses direitos, mas possui na prática um agir de contenção social, mais especificamente, conter determinados grupos e manter os status sociais.

A criminalização desses movimentos é fruto da ideologia predominante de favorecimento das elites, e se perpetua pela mídia, que por meio do capital é manipulada pela boa vontade de quem detém o poder. Nesse contexto, os oprimidos estão "fora da lei", seja fora da sua construção, ou seja, agem contrapondo-se ao Estado.

Nesse contexto, o seguinte trabalho busca em Hannah Arendt, em seus estudos sobre o exercício da cidadania e da politica, abordar a Revolução como parte da luta pela liberdade politica dos Movimentos Sociais e a noção da criminalização como ferramenta de controle social.

A partir da exposição a respeito do Direito e da estrutura de controle dos grupos marginalizados por meio do Direito Penal e dos meios de comunicação de massa, pretende-se analisar a Criminalização no contexto jurídico e social, bem como defender a luta dos Movimentos Sociais, sob a perspectiva da necessidade de mudança completa da estrutura jurídica, por meio da revolução social.

O intuito deste trabalho é, por meio da pesquisa bibliográfica, perceber que a Liberdade Política é parte fundamental da Revolução, e o que define um cidadão é mais do que coexistir dentro das leis que constituem o Estado, é a própria identidade coletiva, os interesses coletivos, que devem ser a pauta de deliberação e formação democrática participativa.

\section{DIREITO E CONTROLE SOCIAL}


O Direito se constitui interligado ao desenvolvimento das relações sociais, a identidade jurídica nasce dos aspectos socioeconômicos que perpassam ao longo do tempo, e é por meio da relação de interpretação que o direito, ao mesmo tempo em que promove a genérica abstração, confere maleabilidade ao caso concreto. Antes da estruturação dogmática romana do Direito com o Corpus Juris Civilis, já se reconhecia na atividade dos logógrafos, uma atuação mais próxima aos advogados de hoje, do que em relação aos oradores nos tribunais, pois esses produziam os discursos que deveriam ser usados na defesa de seus clientes ${ }^{26}$.

Cada discurso tem uma finalidade, uma pretensão que dentro do contexto social se perpassa por uma relação de $\operatorname{poder}^{27}$, e na construção do espaço político ateniense, o denominado por Hannah $\operatorname{Arendt}^{28}$ de Espaço de Aparência, surge da Ação e do discurso dos participantes, um ambiente em que se tornam detentores do espaço de fala e seres políticos.

A Ação em Arendt é conceito chave para se entender a participação política porque só a partir dessa ocupação que nos tornamos de fato cidadãos e detentores de um Direito. E daí porque a estrutura jurídica pode ser concebida como determinador das posições sociais, pois só após a realização do Labor e Trabalho, cumprimento da necessidade humana por meio da transformação dos materiais é que eu posso ter a Ação. Num sentido amplo, a Política é um exercício para os poucos que não dependem da sua força de trabalho para sobrevier. ${ }^{29}$

O que isso produz no Direito? Uma organização hierárquica que não pode ser ocupada por aqueles que precisam consubstancialmente, e para quem o Direito vai funcionar como um limitador social.

A sociedade desenvolveu suas relações baseadas em institutos, organizações, que delimitavam as especificações, ou funções que cada indivíduo deveria ocupar; assim, tem-se desde a divisão de trabalho, nas comunidades no período paleolítico, depois as formações religiosas, e finalmente os institutos de governo, que detinham a legitimidade de atri-

\footnotetext{
${ }^{26}$ WOLKMER, Antonio Carlos. Fundamentos de História do Direito. 8 Ed. Atual. Belo Horizonte - MG: Editora Del Rey. 2014

${ }^{27}$ FOCAULT, Michel. A Ordem do Discurso - Aula Inaugural no Collège de France. São Paulo: Editora Loyola. 2000.

${ }^{28}$ ARENDT, Hannah. A Condição Humana. São Paulo: Forense Universitária e EDUSP, 2008.

${ }^{29}$ Ibidem.
} 
buir funções bem como de sancionar quem não se adequava a essa atribuição.

[...] Como técnica de controle social, que atua mediante a centralização da violência do Estado, o campo jurídico-penal moderno tria por função essencial erguer a positivação de uma dada racionalidade, isto é, um discurso competente, discurso de conhecimento e de poder, capaz de justifica-la. ${ }^{30}$

O Poder e o Direito se fundamentam, e o monopólio do exercício legítimo da violência conduz e qualifica esse exercício de poder, que para tornar-se de fato um controlador social, está interligado a outras esferas. É o poder que se dissemina por entre as entidades sociais dando a cada um, "um poder", "micropoderes" que, segundo Foucault ${ }^{31}$, determinam a forma de o individuo se socializar e se "posicionar" na sociedade. Por meio da estrutura jurídica, criada por um grupo determinado, a sociedade se divide; na definição de Boaventura $^{32}$ : a sociedade é dividida por uma linha, em que do lado de cá, existe o direito, o legal, e do outro o ilegal. "No campo do direito moderno, este lado da linha é determinado por aquilo que conta como legal ou ilegal de acordo com o direito oficial do Estado ou com o direito internacional. O legal e o ilegal são as duas únicas formas relevantes de existência perante a lei, e, por esta razão, a distinção entre ambos é uma distinção universal. ${ }^{33}$

A lógica da construção jurídica é selecionadora; para a manutenção da ideologia, criam-se os mecanismos de controle, que na realização prática condizem às criminalizações. $\mathrm{O}$ serviço sancionador do Estado é o que estabelece o que são condutas coerentes com a predominância normativa, e quem decide essa predominância é o grupo que tem poder.

\footnotetext{
${ }^{30}$ CARVALHO, Thiago Febres. Criminologia, Modernidade, Reconhecimento - A gestão Penal da Exclusão Social nas Aventuras da Modernidade. In: MOREIRA, Nelson Camatta (org). Teoria da Constituição: Modernidade, Identidade e (Lutas por) Reconhecimento. Coleção Direitos Humanos e Democracia. Editora UNIJUÍ - Ijuí. 2015. p. 225.

${ }^{31}$ FOUCAULT, Michel. Microfísica do Poder. Rio de Janeiro: Graal, 1979.

32 SANTOS, Boaventura De Sousa. Para além do Pensamento Abissal: Das linhas globais a uma ecologia de saberes. Revista Crítica de Ciências Sociais, No78, Outubro 2007.

${ }^{33}$ Idem. p. 06.
} 
Normas punitivas vigentes no antigo código penal, como o adultério, são um exemplo do controle, por meio jurídico, de uma determinada ideologia.

"É o direito a arma utilizada pelas instituições formais (e informais) para controlar, limitar, vigiar, estudar, e por fim, dominar as relações de poder" ${ }^{34}$. Chaves Junior ${ }^{35}$, nessa mesma perspectiva compreende o controle social por meio do direito penal como expressão do Estado, e como tal, manifesta-se pela etiquetamento punitivo ${ }^{36}$, que representa a fundamentação prática do direito penal em manter um status estigmatizado de um determinado grupo marginalizado.

Para Foucault ${ }^{37}$, a essência da fundamentação penal é o controle social.No livro "Vigiar e Punir" o panoptismo representa essa organização social que põe indivíduos em constante monitoramento, e a atribuição do poder de vigiar é o que hierarquiza a sociedade, atribui o status, e mantém a organização,

A divisão segundo as classificações ou os graus tem um duplo papel: marcar os desvios, hierarquizar as qualidades, as competências e as aptidões; mas também castigar e recompensar (...) a disciplina recompensa unicamente pelo jogo das promoções que permitem hierarquias e lugares; pune rebaixando e degradando. O próprio sistema de classificação vale como recompensa ou punição ${ }^{38}$.

A questão do panoptismo de Foucault expressa como a prisão moderna e a institucionalização da punição reformulam as formas de suplício da punição penal da Idade Média. O sofrimento físico que servia

34 MOURA, João Carlos da Cunha. A Era da Delegação das Responsabilidades. Editora: Lumen Juris Direito - Rio de Janeiro. 2015. p. 69.

${ }^{35}$ CHAVES JR, Airto. O Controle penal dos Excludentes: as funções simbólicas do direito penal e a eficácia invertida quanto seus objetivos declarados. Publicado em Junho 2011 - Revista Faculdad de Derecho y Ciencias politicas. Vol 41. No114. p. 81-82.

${ }^{36}$ BARATTA, Alessandro. O novo paradigma criminológico: "Labeling Approach", ou Enfoque da Reação social. Negação do Princípio do Fim ou da prevenção. In:

Revau - Rio de Janeiro. 2011.

Criminologia Crítica e Crítica do Sistema Penal. Editora

${ }^{37}$ FOUCAULT, Michel. Vigiar e Punir - Nascimento da Prisão. 23 ${ }^{\text {a }}$ Ed. Petrópolis RJ: Editora Vozes. 2013.

${ }^{38}$ Ibidem. p.151. 
para marcar os indivíduos enquanto delinquentes e marginais, para hierarquizar a sociedade e para moldar o crime ao indivíduo e à posição ocupada, só passa por um processo de legitimação legal, que assim como na Idade Média separa a sociedade e marca determinados indivíduos.

A grande marca desse sistema, porém, não é a formação institucional (controle formal), mas a questão do controle de todos por todos (controle informal): cada indivíduo ocupa um lugar ao mesmo tempo funcional e hierarquizado, formando um quadro espacial, no qual se distribui a multiplicidade de indivíduos para deles tirar o maior número de efeitos possíveis.

Segundo Marcos César Alvarez ${ }^{39}$ o novo poder disciplinar será deste modo, um poder voltado para o "adestramento" dos indivíduos. E, para isso, esse poder utilizará alguns mecanismos simples: o olhar hierárquico, a sanção normalizadora e o exame.

O controle social formal e a vigilância hierárquica induzem, através do olhar, efeitos de poder: o indivíduo adestrado deve se sentir permanentemente vigiado. O exame, por fim, indica uma técnica de controle normalizante que permite qualificar, classificar e punir ininterruptamente os indivíduos que são alvos do poder disciplinar.

[...] O poder disciplinar é, com efeito, um poder, que em vez de se apropriar e de retirar, tem como função maior "adestrar"; ou sem dúvida adestrar para retirar e se apropriar ainda mais e melhor. Ele não amarra as forças para reduzi-las; procura liga-las para multiplica-las e utilizá-las num todo. Em vez de dobrar uniformemente e por massa tudo o que lhe está submetido, separa, analisa, diferencia, leva seus processos de decomposição até às singularidades necessárias e suficientes. ${ }^{40}$

A vigilância é parte fundamental do controle social; de um lado, o direito torna-se o mecanismo de legitimação por meio do sistema penal,

${ }^{39}$ ALVAREZ, Marcos César. Controle social: notas em torno de uma noção polêmica. 2004. São Paulo. vol.18 nº.1 São Paulo Jan./Mar. 2004. Disponível em: $<$ http://www.scielo.br/scielo.php?pid=S0102-

88392004000100020\&script=sci_arttext $>$. Acesso em Nov. 2015.

${ }^{40}$ FOUCAUlT, Michel. Vigiar e Punir - Nascimento da Prisão. $23^{\mathrm{a}}$ Ed. Petrópolis RJ: Editora Vozes. 2013.p.164 
e do fator de criminalização; controlar e punir são sinônimos, e a sociedade incorpora no controle social informal mecanismo de manter os grupos sob um padrão, sendo a família, a escola, a igreja exemplos de instituições que exercem esse controle. A sociedade é o parâmetro de controle, e as diversas formas de expressão refletem a ideologia predominante; a mídia, em geral, mais especificamente a televisiva, não foge à regra e nem à função de vigilância.

\subsection{A comunicação de massa}

Situado em uma perspectiva não menos abrangente está o valor que a mídia (aqui entendida como meios de comunicação em massa) dá ao assunto a ser tratado. O que se observa, em um jogo de relações, é a forma com a qual se dá visibilidade ao fato narrado. A narrativa televisiva, precisamente, opera de forma selecionadora, fomentando certos debates e ocultando outros. De acordo com Bourdieu ${ }^{41}$, a seleção é um princípio moldado de acordo com a busca ao sensacional, ao espetacular.

Nesse sentido, a própria cobertura midiática é um convite de si mesma para si própria, isto é, coloca em cena um resumo de imagens sobre o acontecimento, para que a própria mídia reproduza valores os quais pretendem dar à narrativa, na busca por agilidade de transmissão de informação.

Assim, a ideia de revolução, por exemplo, recebe outros significantes, nomes e enunciados os quais possam parecer extraordinários na medida em que os jornalistas e editores entendem por tal. Para tanto, o discurso jornalístico emprega um método de análise bastante pontual no que se refere aos confrontos, mostrando o fato e aplicando por cima uma narrativa simples e factual do que acontece; eclipsando a que se destinam os atos.

É uma prática industrial, segundo Tarrow ${ }^{42}$, no sentido de que o padrão midiático de emitir discursos é afetado por preferências em eventos dramáticos e visíveis, motivado ainda mais pela competição no qual estão inseridos os diversos sujeitos de um modelo midiático capitalista:

\footnotetext{
${ }^{41}$ BOURDIEU, Pierre. Sobre a televisão. Rio de Janeiro: Jorge Zahar, 1997. p. 25.

42 TARROW, Sidney. O poder em movimento: movimentos sociais e confronto político. Petrópolis: Vozes, 2009. p. 151.
} 
um modelo que vende a notícia, a qual será consumida pelo público. É a maneira que a mídia escolhe para enquadrar uma história que desenvolverá sua rotina lucrativa, com venda de jornais e acumulação de espectadores consumidores.

Importante ressaltar que também a mídia tem papel importantíssimo nas tomadas de posições políticas. Ela influencia e capacita manifestações que podem vir a se tornar movimentos de ruptura revolucionária. Para tanto é necessário utilizar-se estrategicamente de todo o arsenal que a mídia prepara para lançar a notícia do fato. Notório, ainda mais no contexto digital que aliança o mundo cada vez mais rápido, que a carreira da notícia é extensa e veloz, mas também volátil; o fato acontecido já é sabido em poucas horas ou poucos minutos em todo o planeta, porém este pode se extinguir (no sentido de ser ignorado) em poucos dias ou horas. Mais contraditório ainda é a possibilidade de fatos que seriam considerados extremamente importantes se ocorressem insertos em determinadas classes, não terem o alcance de acontecimentos banais.

Não se deveria ignorar o papel do rádio na difusão de informações. Em maio de 1968, por exemplo, os acontecimento na França eram transmitidos respeitosamente pela emissora de rádio do governo, informando as pessoas em diferentes partes do país sobre passeatas, greves e ocupações de fábricas e ajudando a difusão do movimento. Durante a Guerra Fria, a BBC e a Radio Free Europe desempenaram um importante papel na difusão de informações sobre a Europa Oriental, especialmente depois que os dissidentes naqueles países aprenderam como obter relatos noticiosos daquelas fontes de comunicação. ${ }^{43}$

Ocorre que a mídia e os sujeitos que a compõem não são neutros. Mais do que a transmissora do evento ou do fenômeno, a mídia tem uma característica econômica mesmo, de produção. Mais do que um instrumento de registro, torna-se um dos processos de criação da realidade. Bourdieu $^{44}$ afirma que a sociedade é descrita e prescrita pelos meios de

\footnotetext{
43 TARROW, Sidney. O poder em movimento: movimentos sociais e confronto político. Petrópolis: Vozes, 2009. p. 149.

${ }^{44}$ BOURDIEU, Pierre. Sobre a televisão. Rio de Janeiro: Jorge Zahar, 1997. p. 29.
} 
comunicação. Nas suas palavras, "a televisão se torna o árbitro do acesso à existência social e política".

Isso acentua, e é esse o papel estratégico de uma mídia controlada pelos detentores das relações de poder, as tensões entre os militantes do conjunto ativista. Tais tensões tendem a definir outros elementos disruptivos do próprio ativismo, transformando os atos em ações temerárias, alicerçando formas e táticas policiais reprodutoras de repressão. ${ }^{45}$

É nessa perspectiva de produção de subjetividades e discursividades que os meios de comunicação em massa, inseridos em um campo específico de criação de realidade, podem determinar quem pode ou não fazer parte de um modo de ação; em outras palavras, quem pode ser ator do movimento daquilo que ela própria determina como mudança institucional, a qual nada mais é do que a mesma forma institucional praticada de outras maneiras. ${ }^{46}$

As tensões criadas, sejam de ordem subjetiva ou objetiva, determinam, então, no conjunto do processo de movimentos sociais que pode levar à ruptura revolucionária, quem é o "manifestante" e quem é o "baderneiro" no contexto da ação popular. Existe um discurso preparado, de forma disciplinar, para que este ou aquele sujeito possa ou não interagir no contexto da mobilização. Assim, se confirma a estratégia de criação da realidade. Lança-se para o público a ideia de que está sendo preparada outra forma de ação política, novas formas e novos atores, mas, na verdade, o enunciado apenas se transfigura em outros indivíduos e sujeitos. Aquilo que é criado como produção de novas categorias políticas e revolucionárias é, em verdade, a reprodução dos mesmos instrumentos de controle.

Os jornalistas - deve-se dizer o campo jornalístico devem sua importância no mundo social ao fato de que detêm um monopólio real sobre os instrumentos de produção e difusão em grande escala da informação, e, através desses instrumentos, sobre o acesso dos simples cidadãos, mas também dos outros

\footnotetext{
${ }^{45}$ KIELBOWICS Richard; SCHERER, Clifford. The role of the press in the dynamics of social movements. In: Research in social movements, conflicts and changes. Greenwich, Conn.: JAI, 1986. p. 86.

${ }^{46}$ FOCAULT, Michel. A Ordem do Discurso - Aula Inaugural no Collège de France. São Paulo: Editora Loyola. 2000.
} 
produtores culturais, cientistas, artistas, escritores, ao que se chama por vezes de "espaço público", isto é à grande difusão. ${ }^{47}$

É nessa perspectiva que, para determinar-se como um espaço ontológico de notícia, o fato precisa ser inserido nesse campo e devolvido em forma de notoriedade. Para alcançar tal notoriedade, é necessário passar, paradoxalmente, por um campo de censura, retalhado e reproduzido conforme seja capaz de prender a atenção. Mudanças bruscas no sistema burguês político e valorativo serão retalhadas de forma a prender a atenção conforme os produtores e consumidores (burgueses) esperam.

Molotch ${ }^{48}$ afirma que, é necessário notar que o movimento industrial de produção midiática não é ligado necessariamente a outro sujeito: nem ao governo, nem ao movimento social. Em outras palavras, como está inserida no contexto mercadológico, a mídia tem uma espécie de dever de se ater àquilo que pode gerar margem de acúmulo de capital nas trocas entre a produção da realidade e o consumo desta realidade.

Isso é extremamente importante quando se analisa o contexto de produção e consumo midiáticos. O espectador, muitas vezes, sabe que um fato é narrado em decorrência daquilo que se espera seja narrado. Uma partida de futebol, por exemplo, não necessita de mais do que o ocorrido durante a partida, o escore final e algum fato extra que realmente tenha necessidade ser noticiado (uma expulsão de jogador, uma briga entre os atletas etc.), sem a necessidade de exibição de dados de quantas pessoas estavam trajando o uniforme do time da casa. A incompletude, em certos casos, é aceita. Por vezes, como no caso aqui estudado, a incompletude é a forma de tornar visível apenas aquilo que o narrador/jornalista quer que seja consumido e transformado em discurso.

Becker ${ }^{49}$, analisando métodos de representação da sociedade, afirma que o usuário (consumidor, indivíduo que lê e vê a notícia) também é produtor de sentidos. Cabe ao usuário checar possibilidades, criar hipóteses, construir categorias e análises, enfim, é também parte de uma

\footnotetext{
${ }^{47}$ BOURDIEU, Pierre. Sobre a televisão. Rio de Janeiro: Jorge Zahar, 1997. p. 65.

48 MOLOTCH, Harvey; LESTER, Marilyn. Accidental News - The Great oil spill as local occurence and as national event. American Journal of Sociology. n.81. 1979, p. 79.

49 BECKER, Hoard Saul. Outsiders: estudos de sociologia do desvio. $2^{\mathrm{a}}$ Ed. Rio de Janeiro: ditora Jurge Zahar. 2009. p. 58.
} 
espécie de divisão do trabalho, isto é, o entendimento do consumidor é necessário para se completar o ciclo de transmissão da informação.

Entretanto, a forma industrializada que a mídia tem já prepara o conteúdo ministrado. Todos os enunciados e práticas discursivas ${ }^{50}$ já preparam o campo para um entendimento específico do consumidor. Muitas vezes, o próprio consumidor já espera o conteúdo preparado para mera apreciação consumerista.

Os movimentos sociais de ruptura que levam à revolução, não têm o controle de meios de produção midiáticos, no máximo podem se utilizar de forma estratégica desses instrumentos. Porém, de acordo com Tarrow $^{51}$ a ideia por si só de ruptura pressupõe impedimento de atividades rotineiras daqueles que se lhe opõem, também daqueles consumidores da produção midiática, forçando-os a se não acatar, pelo menos dar atenção às reivindicações.

Essa ruptura na ordem das coisas cria constrangimento para os controladores das relações de poder, gerando, ao fim e ao cabo, novas estratégias de repressão, transformando o ataque unilateral do aparelho policial do Estado em "confronto entre manifestantes e policiais".

\subsection{A criminalização da revolução}

Analisando o papel de controle do Direito, a forma como a mídia de massa tem determinado opiniões e condutas a determinados sujeitos é que a Criminalização torna-se um questionável e discutível enquanto função única e exclusiva de mantedora da paz social.

Segundo Zaffaroni ${ }^{52}$, o tipo penal é "um instrumento legal, logicamente necessário e de natureza predominantemente descritiva, que tem por função a individualização de condutas humanas penalmente relevantes (por estarem penalmente proibidas)". Tendo o Direito uma função de controle social, é nítido que o tipo penal é fruto de uma pretensão da mo-

\footnotetext{
${ }^{50}$ FOCAULT, Michel. A Ordem do Discurso - Aula Inaugural no Collège de France. São Paulo: Editora Loyola. 2000.

51 TARROW, Sidney. O poder em movimento: movimentos sociais e confronto político. Petrópolis: Vozes, 2009. p. 128.

52 ZAFFARONI, E. Raúl \& PIERANGELI, José Henrique. Manual de direito penal

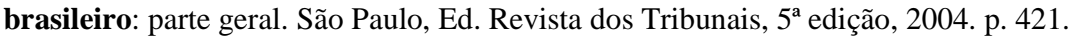


ralidade vigente, daí porque Zaffaroni ${ }^{53}$ entende a criminalização em duas etapas: a criminalização primária "é o ato e o efeito de sancionar uma lei penal material que incrimina ou permite a punição de certas pessoas" e a criminalização secundária "é a ação punitiva exercida sobre pessoas concretas, que acontece quando as agências policiais detectam uma pessoa que supõe-se tenha praticado certo ato criminalizado primariamente". ${ }^{54}$

A partir disso é que a criminalização dos Movimentos sociais não se perfaz somente na tipificação da conduta de "manifestação" ou mesmo de "ser parte de movimento social", mas sim da prática ideológica que "tipifica" socialmente as minorias que se rebelam contra arbitrariedades do sistema.

A prisão de 19 manifestantes no Rio de Janeiro, antes da final da Copa do Mundo, e de dois em São Paulo, em protesto no dia 23 de junho, preocupa sociólogos e pesquisadores dos novos movimentos sociais. [...]'Apontar alguns manifestantes que participam desses movimentos como líderes ou chefes de quadrilha está em desacordo com as dinâmicas sociais que temos observado nos nossos estudos', diz a nota que serve como um manifesto contra a criminalização dos protestos. 'Adesão a protestos de rua é espontânea; não há quadrilha nem associação' ${ }^{55}$

O caráter "jurídico", em sua maioria arbitrário, de prisões que ocorrem em meio a manifestações, ou ocupações políticas, contribui para descaracterizar a prática de reivindicação dos movimentos.

O juízo das pessoas é trocado por um aparelho de consenso imposto midiaticamente: elementos, dados, códigos etc. são assimilados pelo poder dos meios de comunicações e sistemas políticos e econômicos que os regem.

\footnotetext{
${ }^{53}$ Idem. p. 43.

${ }^{54}$ Ibidem.

55 HUFFPOST BRASIL. Criminalização dos movimentos sociais: pesquisadores defendem que protestos de rua não têm formação de quadrilha. Publicado em 15/07/2014. Disponível em:<http://www.brasilpost.com.br/2014/07/15/protestocrime_n_5589269.html>. Acesso em Abril/2016.
} 
A participação política é desmotivada através da transmissão de enunciados sobre uma suposta faceta violenta (simbólica) do movimento. Um exemplo ocorreu no estado do Rio de Janeiro: a Lei 6.528/2013, curiosamente visa, conforme ementa, a "regulamentar o artigo 23 da Constituição do Estado", ainda que o artigo mencionado não suponha qualquer previsão de regulamentação. Dadas as táticas "Black Blocs" nas manifestações que começaram a ocorrer no Brasil, em seu artigo $2^{\circ}$, esta lei proibiu o "uso de máscara ou qualquer outra forma de ocultar o rosto do cidadão com o propósito de impedir-lhe a identificação".

Apropriou-se de uma conduta simbólica (o uso das máscaras) como maneira de promover sensação de segurança para a população e "manifestantes pacíficos" (já que estas categorias eram bombardeadas midiaticamente com a ideia do "vandalismo"), como se apenas pessoas que cobrissem o rosto fossem responsáveis pelos atos praticados. Daí "uma série de ilegalidades surge em lutas onde sabemos que se defrontam ao mesmo tempo a lei e a classe que a impôs". ${ }^{56}$

Dessa forma, os movimentos revolucionários que pressupõem ruptura da ordem estabelecida, são noticiados como forma de violência orquestrada, principalmente aquelas encontradas nos momentos de demonstração de protestos. É o que se observou com as notícias sobre os "Black Blocs", ressaltando um aspecto violento dessas táticas direcionadas à propriedade material, (como bancos, pontos de ônibus, vidros de estabelecimentos comerciais etc.) fazendo parecer que a violência do aparelho policial do Estado nesse contexto fosse qualquer coisa justificável. Gans ${ }^{57}$ explica que a mídia tende a fazer enquadramentos noticiosos em cima do fato que ontologicamente pode ser considerado notícia; é assim que a discussão sobre a ruptura política, atravessada pela massa uniforme de pessoas, perde valor quantitativo e qualitativo para a ferramenta midiática quando um estudante solitário lança uma pedra contra uma vidraça de um banco ou um travesti encena a crucificação simbolizando o sofrimento de uma classe.

A Criminalização é fruto da tanto da manipulação midiática, quanto da arbitrariedade do sistema punitivo, pois ambas correspondem à

\footnotetext{
${ }^{56}$ FOUCAULT, Michel. Vigiar e Punir - Nascimento da Prisão. 23a Ed. Petrópolis - RJ: Editora Vozes, 2013. p. 260.

${ }^{57}$ GANS, Herbert. Deciding what's News: a study of the CBS Evening News, NBC Nightly News, Newsweek and Time. Nova York: Pantheon, 1979. p. 169
} 
mesma relação de ideologia; são mecanismos de poder e deles é que decorrem as articulações sobre a quem se deve aplicar a sanção.

\section{OS MOVIMENTOS SOCIAIS}

Construída por uma motivação racional, a cidadania, ao longo do tempo, teve diferentes definições, entre uma tênue existência entre a moralidade e o direito, o cidadão, aquele que dentro de uma sociedade exerce e tem poder de direito, por vezes nos remete à acepção grega do termo, que incluía apenas determinadas pessoas de uma elite.

Com o ápice das revoluções, a cidadania passa a do exercício político, para a legitimação constitucional, a declaração do homem e do cidadão, expressamente desenvolve uma cidadania positivista que determina direitos e deveres do cidadão, e que, carregou a tradição de ser um conceito atendente a um determinado grupo. Mais que discutir o que é a cidadania, o problema maior está em "quem é o cidadão".

É a partir do surgimento do Estado de Bem-Estar Social que o conceito de cidadania passa a significar ter direitos sociais. Então cidadão é aquele que tem direito a ter direitos. [...] Assim começa o Estado Social de Direito, cuja origem é híbrida, fruto de um compromisso entre tendências ideológicas opostas: por um lado representou uma conquista do socialismo democrático, por outro uma vitória do pensamento liberal mais progressista. A ideia de cidadania passa a apontar para uma base igualitária dos direitos e exigia, portanto, a eliminação de qualquer obstáculo que impedisse alcançar a independência pessoal indispensável para ser cidadão. A pobreza passa a ser vista não mais como uma questão individual, mas social que exigia intervenção política. ${ }^{58}$

58 GORCZEVSKI, Clovis; MARTIN, Nuria Belloso: A necessária revisão do conceito de cidadania: movimentos sociais e novos protagonistas na esfera pública democrática. $1^{\text {a }}$ edição. Santa Cruz do Sul : EDUNISC, 2011. p. 53. 
A cidadania social reflete as construções pós-guerra, que fundamentam os direitos humanos e a crescente constitucionalização das relações, os direitos fundamentais, e com isso, a construção jurídica tem a função de garantir e promover esses direitos.

$\mathrm{Na}$ ideia de direitos sociais, por mais que tenham um apoio e uma fundamentação dentro do direito, percebe-se um discurso de inserção e exclusão, que é dado de acordo com a posição política e jurídica de cada sujeito, e a estrutura de marginalização e determinação social promovem uma separação, que coloca o "outro" à margem desses direitos e da sua reivindicação. ${ }^{59}$

Na concepção Arendiana, a cidadania perpassa por uma prática de uma identidade coletiva, em que o interesse público reflete as discussões, debates e a participação dos indivíduos no meio político. Essa concepção participativa de cidadania a coloca como um processo de decisões, produzida num modelo discursivo e democrático.

Na opinião de Arendt, apenas a partilha do poder que vem do engajamento cívico e a decisão comum pode prover cada cidadão de um senso de sujeito político efetivo. Com uma crítica à representação que priva o exercício direto da democracia.

As comunidades políticas, nas quais os homens se tornam cidadãos, são produzidas e preservadas por leis; e tais leis, feitas pelos homens, podem variar muito e poder dar forma a inúmeros tipos de governo, todos eles, de uma maneira ou de outra, tolhendo a vontade livre de seus cidadãos. ${ }^{60}$

$\mathrm{Na}$ "Condição Humana", Arendt coloca o espaço político na definição das experiências gregas no espaço da polis, a comunidade política, que deve ser o ambiente em que os iguais deliberam a respeito da democracia, num exercício de liberdade, de participação política na qual o homem se tornava sujeito politico,

${ }^{59}$ MOURA, João Carlos da Cunha. A Era da Delegação das Responsabilidades. Editora: Lumen Juris Direito - Rio de Janeiro. 2015. p. 81.

${ }^{60}$ ARENDT, Hannah. A Vida do Espírito. Rio de Janeiro: Relume Dumará, 1995.p. 335. 
Ser livre significava ao mesmo tempo não estar sujeito às necessidades da vida nem ao comando de outro e também não comandar. Não significava domínio, como também não significava submissão. ${ }^{61}$

A cidadania participativa, o agir político é o que definiria esse cidadão, e a concepção do estado social e a ideia da existência de um direito fundamental pressupõem o direito de reivindicação; mais que saber de política, o cidadão deve nascer da sua prática, e se um governo tolhe essa participação, uma nova forma de governo nascida da decisão da comunidade é necessária.

Os movimentos sociais, aqui tratados não só como grupos de demandas específicas, mas como um todo que compartilha da luta contra a marginalização e opressão estatal ${ }^{62}$, enquadram-se não só como importantes agentes de reivindicação de direitos, mas também questionam a estrutura da elite hierarquizada, como uma rede mobilizada de indivíduos, grupos e organizações com um sentido muito desenvolvido da identidade coletiva, perseguem o objetivo cujo logro tem consequências para toda a sociedade e não somente para o grupo portador da reivindicação ou o conjunto de reivindicações, "problematizam os modelos culturais, normas, identidades ou instituições presentes em uma sociedade. Assim, os movimentos sociais entram em interação com ambas as esferas da vida social: o Estado e a sociedade civil". ${ }^{63}$

Na luta, os movimentos sociais brasileiros tornaram-se organizações voltadas a buscar acesso a diversos direitos como o direito à terra, à moradia, ao reconhecimento jurídico social (movimentos LGBT e Feministas) e, nas diversas diretrizes, a mobilização e o senso de solidariedade mantêm o impulso em romper com a marginalização e hierarquização social.

Os movimentos sociais são formados pelos grupos que estão sujeitos ao controle do sistema jurídico-penal, e, enquanto organizações

${ }^{61}$ ARENDT, Hannah. A Condição Humana. São Paulo: Forense Universitária e EDUSP, 2008. p. 41.

${ }^{62}$ GORCZEVSKI, Clovis; MARTIN, Nuria Belloso: A necessária revisão do conceito de cidadania: movimentos sociais e novos protagonistas na esfera pública democrática. $1^{\text {a }}$ edição. Santa Cruz do Sul : EDUNISC, 2011. p. 33.

${ }^{63}$ GORCZEVSKI, Clovis; MARTIN, Nuria Belloso: A necessária revisão do conceito de cidadania: movimentos sociais e novos protagonistas na esfera pública democrática. $1^{\text {a }}$ edição. Santa Cruz do Sul : EDUNISC, 2011.p. 33. 
sociais pela emancipação, enfrentam o mesmo embate e opressão sistemática. Por meio da criminalização, das duras repressões policiais e das prisões arbitrárias, a elite perpetua o status, e o sistema penal surge em razão de manter essa ordem.

Nessa questão, o Estado brasileiro perpetua um sistema de marginalização que não promove a integração da política, nem as reivindicações sociais, ainda que a política representativa esteja atuando numa frente de ocupação interna do direito, a própria forma como a luta social é debatida tende à estigmatização.

O judiciário e o Legislativo, ao examinarem as ações promovidas pelos movimentos socais, contribuem para a manutenção de uma ordem injusta e desigual, que se esconde sob os princípios da liberdade e da justiça. A legislação nacional e internacional é manipulada de acordo com os interesses da classe dominante, restando impossível o respeito e a observância dos direitos humanos. ${ }^{64}$

Assim, percebe-se que os movimentos sociais vivem sem saída, dentro de um direito que não dá espaço aos seus questionamentos e participação politica e, ao mesmo tempo, marginaliza-os, e criminaliza suas ações de luta. A lei torna-se a barreira entre o direito e a justiça, e o Estado, o portão que separa quem tem poder, de quem vive fora da lei na marginalidade.

\section{O DIREITO A REVOLUÇÃO}

O Estado de exceção constante do oprimido suspende de uma parte da sociedade, qualquer direito ou possibilidade de reivindicação, pois a forma como o sistema se estrutura impede que os próprios mecanismos legais sejam usados à finalidade social. O grupo marginalizado permanece à margem, e sob o controle da sociedade, da mídia e do sistema formal.

64 MNDH - Movimento Nacional de Direitos Humanos. A Criminalização dos Movimentos Sociais no Brasil - Relatório de Casos exemplares. Brasília, Outubro de 2006. p. 14. 
O "outro" é submetido a uma existência em hiatos. A construção jurídica é um excesso de leis e burocracias que aumentam esses espaços, e coexiste com esse direito, um "outro" que não está dentro dessa "lei", pois as leis não são para ele, e nem pensadas por ele. Então, ainda que, abstratamente, tenha um pressuposto de participação, seja por um direito humano ou por um direito fundamental, ou por uma razão de necessidade, a hierarquização e manipulação do sistema jurídico brasileiro aprisiona, literalmente, as tentativas de romper uma tradição elitista e promover a equidade.

Nesse ponto, os movimentos sociais, são mais que, como já dito, grupos de reivindicação política, na busca por direitos; eles questionam toda essa estrutura hierárquica segregadora, que vai desde a separação de classes ao patriarcado que se perpetua em diversas instituições.

Nessa perspectiva a respeito do Direito:

[...] O que o direito, sob um discurso garantidor de liberdade, faz surgir, na verdade uma forma repressiva das relações. Por serem os elementos o Direito (lei, norma, legislação, burocratização, etc) em si mesmo objetos, objetivados torna-se o próprio Direito - a cadeira se estende até a objetivação/reificação os sujeitos e de suas relações. ${ }^{65}$

Explica ainda Foucault ${ }^{66}$, que o Direito existe em função da própria propriedade, ou seja, pela estrutura ideológica que rege a sociedade é que se estabelecem os parâmetros, e quem, nesse contexto, deve ser punido:

Neste caso, o problema torna-se muito difícil. E do ponto de vista da propriedade que há roubo e ladrão. Direi para concluir que a reutilização de uma forma como a do tribunal, com tudo o que ela implica posição do juiz como terceiro termo, referência a um direito ou a uma equidade, sentença decisiva - deve

65 MOURA, João Carlos da Cunha. A Era da Delegação das Responsabilidades. Editora: Lumen Juris Direito - Rio de Janeiro. 2015. p. 71.

${ }^{66}$ FOUCAULT, Michel. Microfísica do Poder. Rio de Janeiro: Graal, 1979. p. 68-69. 
também passar pelo crivo de uma critica muito severa; e eu só vejo re-utilização válida para ela no caso em que se possa, paralelamente a um processo burguês, abrir um contra-processo que faça aparecer como mentira à verdade do outro, e como abuso de poder as suas decisões. Além deste caso, vejo mil possibilidades de guerrilha judiciária ou de atos de justiça popular, que não passam pela forma do tribunal. ${ }^{67}$

Portanto, a função mantedora desse direito transforma os indivíduos em meros espectadores da ideia de uma democracia, "estão agraciados com benefícios, porém não podem lutar por eles e nem constrangêlos, são cercados por um conjunto de relações não criativas, moldadas pelo Direito do sistema imposto (e que se impõe)". ${ }^{68}$

Quando percebemos a realidade estagnada do sistema jurídico, tem-se um porquê das crescentes manifestações dos movimentos sociais que ocupam ruas, escolas, faculdades, numa tentativa de promover o sistema, e sempre são duramente contidos.

A criminalização dos movimentos sociais reflete o controle para a manutenção dos status, e frente às injustiças sociais, o debate deixa de ser de direitos positivados, para o exercício de um direito à revolução.

[...] Onde ontem, isto é, bons tempos do Iluminismo, apenas o poder despótico do monarca parecia se interpuser entre o homem e sua liberdade de agir, de repente havia surgido uma força muito mais poderosa que obrigava os homens a seu bel-prazer, e da qual não havia escapatória, saída o revolta possível: a força da história e da necessidade histórica. ${ }^{69}$

Hannah Arendt baseia o seu conceito de liberdade no exercício político grego, mas trata na modernidade do enriquecimento da liberdade

\footnotetext{
${ }^{67}$ Idem. p. 68.

68 MOURA, João Carlos da Cunha. A Era da Delegação das Responsabilidades. Editora: Lumen Juris Direito - Rio de Janeiro. 2015. p. 71.

${ }^{69}$ ARENDT, Hannah. Sobre a Revolução. Editora Companhia das Letras - São Paulo. 2011.p. 83.
} 
no desenrolar das revoluções, pois a finalidade da revolução é a libertação política. Revolucionar amplia os sentidos que o termo cidadania carrega consigo, a respeito do exercer seus direitos, parafraseando Celso Lafer (1998), a necessidade histórica das opressões fez com que existisse, segundo Hannah Arendt um direito a ter direitos, que não se legitima pelo Estado, mas pela associação dos grupos.

É a possibilidade dos homens estabelecerem uma comunidade política que seja baseada na liberdade, "portanto a ideia de que a liberdade e a experiência de um novo princípio devem coincidir é crucial para a compreensão das revoluções na idade moderna. ${ }^{70}$

Os movimentos sociais agem à margem da lei, e a mídia e a própria sociedade acabam por perpetuar essa criminalização. Em se tratando da revolução, os grupos estão à margem do direito criado por determinadas pessoas, mas atuam dentro de uma legitimidade social que é o direito de pertencer a uma comunidade politica.

Um conceito que está intimamente relacionado a isso é a Desobediência Civil, pensada por Thoreau, como o exercício legítimo da ilegalidade, da violência, como forma de resistência à opressão do sistema. Hannah Arendt concebe num mesmo conceito, uma perspectiva distinta que é a defendida aqui:

A desobediência civil tende a ser uma ação coletiva, que assume as características de um direito individual que só pode ter sucesso se grande numero de pessoas o exercerem em conjunto e de maneira convergente. [...] Daí a relevância da dimensão exemplar da desobediência civil e a sua conclusão de que a não-violência é a única alternativa política adequada à violência do "sistema". ${ }^{71}$

O exercício da violência é uma grande diferença concebida por Arendt, por entender que o poder não advém do uso legítimo da violência; o poder é entendido como a aptidão humana de agir em conjunto. A questão da obediência à lei não se resolve pela força, como tradicionalmente a revolução é conceituada, a violência como a dor do parto da re-

\footnotetext{
${ }^{70}$ Idem. p. 33.

${ }^{71}$ LAFER, Celso. A Reconstrução dos Direitos Humanos: Um diálogo com o Pensamento de Hannah Arendt. Editora Companhia das Letras - São Paulo. 1998. p. 201.
} 
volução e da igualdade, uma concepção que remete à Revolução Francesa, mas "sim pela opinião e pelo número daqueles que compartilham o curso comum de ação". ${ }^{22}$

O que não que não impede que a violência seja um ato de resistência à opressão: ela só deve atuar como reação. A violência de um contra todos é injusta, mas de um todo, deixa de ser um ato de violência indiscriminado e torna-se parte da luta, ainda que não seja a regra,

A resistência violenta à opressão é vista como reação ao desaparecimento da reciprocidade de direitos e deveres entre governantes e governados, desempenhando a discussão sobre a licitude ou ilicitude da resistência a função de examinar se os meios são adequados aos fins. ${ }^{73}$

A revolução está ligada à fundação de um novo governo, e o problema está numa fundação baseada na violência, pois ainda que a força e a violência sejam marginais ao exercício político, constituem uma forma de dominação, que pode preservar os espaços políticos assim como destruí-los, pois não constitui atividade política em si, e ela remete essa associação direita da violência para revolucionar a influência do teórico absolutista Maquiavel, que entende política como dominação, em que os fins justificam os meios.

"A distância entre o Direito formalmente válido e a realidade social não significa, no entanto, que a desobediência civil possa ser considerada como uma variante adicional da crescente conduta ilícita". (LAFER, 1998, p.229). A desobediência civil é um conceito que se relaciona aos movimentos sociais, não numa tentativa de legitimar a violência, mas sim porque a desobediência trata-se dessa "associação voluntária que tem como objetivo mostrar a sua força numérica e diminuir o poder moral da maioria" (LAFER, 1998, p.232).

É nessa associação que o direito à revolução se concretiza: "Não precisa ser um grande número; como disse Mirabeau, dez homens reunidos podem fazer tremer 100 mil que estão separados" (ARENDT, 2011, p.159), pois não há mudança motivada por uma pessoa, e por isso

72 Idem. p. 205.

${ }^{73}$ Idem. p. 210. 
critica essa violência programada, porque ela carrega um ímpeto de anarquismo e totalitarismo, em que a sociedade é suprimida e o exercício dos direitos se concretiza em grupo.

\section{CONSIDERAÇÕES FINAIS}

$\mathrm{O}$ ato de revolucionar nasce da necessidade de romper com as barreiras impostas pela política elitizada e de viabilizar a realização de uma democracia que de fato seja composta pela ideia de um povo. Mais que a intenção de ter certos direitos garantidos, as manifestações socais almejam ingressar no debate político em posição de igual relevância. Para Hannah Arendt, tratar desse ato revolucionário está ligado à superação da estrutura segregadora do Direito, e da legitimidade de reivindicação dos que constituem em sua maioria os marginalizados por esse sistema.

Uma razão fundamental está justamente no "ser maioria", pois a Revolução não se faz do interesse de um, mas da ação de muitos. O Direito, historicamente um artifício de manutenção de poder, é um parâmetro a ser superado nessa Revolução, e nem por isso fala-se em uma noção de arbitrariedade social: trata-se de superar um modelo de Direito em prol de outro que seja construído pelos diversos grupos socais.

Os movimentos sociais, nesse parâmetro, deixam de ser tratados enquanto reivindicadores de um direito específico (terra, direito das mulheres, LGBT, etc.) e se consolidam como agentes da revolução, ou seja, grupos que encontram no espaço de luta social seu exercício político e a partir deles é possível se questionar toda a estrutura jurídica. De fato, não se trata de conceder direitos, mas de perceber nas constantes lutas, manifestações e demandas sociais, que o Direito que temos nasce de poucos, e reconhece estes poucos, e por isso que não há por que se falar em criminalizar, porque esse Direito, não é de fato legitimado para tal: ele reflete o que a ideologia da elite social determina.

O direito de revolucionar nasce no seio das necessidades das "minorias" socais que representam muitos, quando agem contra o sistema jurídico penal. O espaço político é construído em sociedade, e a criminalização do agente, que atua dentro das manifestações sociais, ou o estereótipo de criminoso a ele atribuído, representam a forma do sistema se impor e conter essas condutas. Para alcançar a Revolução, o começo está no reconhecimento das lutas sociais conjuntas, que não recorrem somente 
à concessão de direitos, mas à mudança de fato da estrutura jurídica, fonte da separação social e da marginalização.

\section{REFERÊNCIAS BIBLIOGRÁFICAS}

ADORNO, Theodor W; HORKHEIMER, Max. A Indústria Cultural: O Esclarecimento Como Mistificação das Massas. Dialética Do Esclarecimento - Fragmentos Filosóficos. Disponível em:< https://direitoufma2010.files.wordpress.com/2010/05/a-industriacultural.pdf> .Acesso em Nov.2015.

ALVAREZ, Marcos César. Controle social: notas em torno de uma noção polêmica. 2004. São Paulo. vol.18 nº.1 São Paulo Jan./Mar. 2004. Disponível em: <http://www.scielo.br/scielo.php?pid=S010288392004000100020\&script=sci_arttext >. Acesso em Nov. 2015. ARENDT, Hannah. Sobre a Revolução. Editora Companhia das Letras São Paulo. 2011.

Universitária e EDUSP, 2008.

Dumará, 1995.

A Vida do Espírito. Rio de Janeiro: Relume

BECKER, Hoard Saul. Outsiders: estudos de sociologia do desvio. $2^{\text {a }}$ Ed. Rio de Janeiro: ditora Jurge Zahar. 2009.

BENJAMIN, Walter. O anjo da História. Editora Autêntica - Belo Horizonte. 2012.

BRITTOS, Valério C; GASTALDO, Édison. Mídia, poder e controle social. Disponível em: $<\quad$ http://revistaalceu.com.pucrio.br/media/alceu_n13_Brittos\%20e\%20Gastaldo.pdf $>$ Acesso em: Nov. 2015.

BOURDIEU, Pierre. Sobre a televisão. Rio de Janeiro: Jorge Zahar, 1997.

CARVALHO, Thiago Febres. Criminologia, Modernidade, Reconhecimento - A gestão Penal da Exclusão Social nas Aventuras da Modernidade. In: MOREIRA, Nelson Camatta (org). Teoria da Constituição: Modernidade, Identidade e (Lutas por) Reconhecimento. Coleção Direitos Humanos e Democracia. Editora UNIJUÍ - Ijuí. 2015. 
CHAVES JR, Airto. O Controle penal dos Excludentes: as funções simbólicas do direito penal e a eficácia invertida quanto seus objetivos declarados. Publicado em Junho 2011 - Revista Faculdad de Derecho y Ciencias politicas. Vol 41. Nº114.

BARATTA, Alessandro. O novo paradigma criminológico: "Labeling Approach", ou Enfoque da Reação social. Negação do Princípio do Fim ou da prevenção. In: Criminologia Crítica e Crítica do Sistema Penal. Editora Revau - Rio de Janeiro. 2011.

DALMONTE, Edson Fernando. Estudos culturais em comunicação: da tradição britânica à contribuição latino-americana. São Paulo, ano I, n. $2, \quad$ nov/2002. $\quad$ Disponível em:〈http://www.infoamerica.org/documentos_pdf/dalmonte.pdf $>$ Acesso em Nov.2015.

FOUCAULT, Michel. A arqueologia do saber. 7ed. Rio de Janeiro: Forense Universitária, 2008.

. Vigiar e Punir - Nascimento da Prisão. $23^{\mathrm{a}} \mathrm{Ed}$. Petrópolis - RJ: Editora Vozes. 2013.

. Microfísica do Poder. Rio de Janeiro: Graal, 1979.

A Ordem do Discurso - Aula Inaugural no Collège de France. São Paulo: Editora Loyola. 2000.

GANS, Herbert. Deciding what's News: a study of the CBS Evening News, NBC Nightly News, Newsweek and Time. Nova York: Pantheon, 1979.

GORCZEVSKI, Clovis; MARTIN, Nuria Belloso: A necessária revisão do conceito de cidadania: movimentos sociais e novos protagonistas na esfera pública democrática. $1^{\mathrm{a}}$ edição. Santa Cruz do Sul : EDUNISC, 2011.

HUFFPOST BRASIL. Criminalização dos movimentos sociais: pesquisadores defendem que protestos de rua não têm formação de quadrilha. Publicado em 15/07/2014. Disponível em: <http://www.brasilpost.com.br/2014/07/15/protestocrime_n_5589269.html>. Acesso em Abril/2016.

KIELBOWICS Richard; SCHERER, Clifford. The role of the press in the dynamics of social movements. In: Research in social movements, conflicts and changes. Greenwich, Conn.: JAI, 1986. 
LAFER, Celso. A Reconstrução dos Direitos Humanos: Um diálogo com o Pensamento de Hannah Arendt. Editora Companhia das Letras São Paulo. 1998.

MOLOTCH, Harvey; LESTER, Marilyn. Accidental News - The Great oil spill as local occurence and as national event. American Journal of Sociology. n.81. 1979, p. $235-260$.

MOURA, João Carlos da Cunha. A Era da Delegação das Responsabilidades. Editora: Lumen Juris Direito - Rio de Janeiro. 2015.

MNDH - Movimento Nacional de Direitos Humanos. A Criminalização dos Movimentos Sociais no Brasil - Relatório de Casos exemplares. Brasília, Outubro de 2006.

SANTOS, Boaventura De Sousa. Para além do Pensamento Abissal: Das linhas globais a uma ecologia de saberes. Revista Crítica de Ciências Sociais, Nº 78 , Outubro 2007.

TARROW, Sidney. O poder em movimento: movimentos sociais e confronto político. Petrópolis: Vozes, 2009.

WOLKMER, Antonio Carlos. Fundamentos de História do Direito. 8 Ed. Atual. Belo Horizonte - MG: Editora Del Rey. 2014

ZAFFARONI, E. Raúl \& PIERANGELI, José Henrique. Manual de direito penal brasileiro: parte geral. São Paulo, Ed. Revista dos Tribunais, $5^{\text {a }}$ edição, 2004. 
